\title{
AN ELECTRONIC DESIGN OF A LOW COST BRAILLE HANDGLOVE
}

\author{
M.Rajasenathipathi ${ }^{1}$, M.Arthanari ${ }^{2}$, and M.Sivakumar ${ }^{3}$ \\ ${ }^{1}$ Assistant Professor in Computer Science, N.G.M. College-642001, Tamilnadu, India. \\ ${ }^{2}$ Director, Bharathidasan School of Computer Applications, Ellispettai-638116, Tamilnadu, India \\ ${ }^{3}$ Doctoral Research Scholar, Anna University, Coimbatore, Tamilnadu, India \\ ${ }^{1}$ Senathi_pathi@yahoo.co.in, ${ }^{2}$ arthanarimsvc@gmail.com, ${ }^{3}$ sivala@gmail.com
}

\begin{abstract}
This paper documents a new design for a Braille Hand glove, comprising of a majority of electrical components, the design aims to produce a product to perform vibrations in six position of blind's person right hand. A low cost and robust design will provide the blind with an affordable and reliable tool also it produce the new technique and communications method for blind persons.
\end{abstract}

Keywords- Braille, cell, vibration, dots, motor.

\section{INTRODUCTION}

Braille is an important language used by the blind to read and write. It is vital for communication and educational purposes. The Braille code has become the main system for the majority of those blind people who read and write using tactile means, and can be found in many countries around the world. Braille uses raised dots in groups of six which were arranged in three rows to two. These six arranged in three rows to two. These six positions which can be raised or flat, are used in combination to give just 64 different Braille characters. This clearly means that there can be a one to one correspondence between Braille characters and text. The blind person touch raised dots and understands the English characters. The proposed Braille Hand glove contains six vibrations motors in five fingers and center palm. These six positions are matched to six values of Braille code. So instead of touching the raised Dots in Braille sheet, this Braille Hand glove produces vibration based on English character value.

\section{BACKGROUND DETAILS}

\section{A. What is Braille}

All over the world, persons with visual handicaps have used Braille as the primary means to reading information. Also, the concept of Braille has been accepted as a universal approach that works across the boundaries of the world. Different countries of the world have adapted the system of Braille to suit their languages. Irrespective of these changes or modifications, Visually Handicapped persons understand standard Braille for the Roman alphabet (English Braille) making it possible to exchange information in a consistent fashion across different countries.

\section{B. Brief Introduction to Braille}

Standard Braille is an approach to creating documents which could be read through touch. This is accomplished through the concept of a Braille cell consisting of raised dots on thick sheet of paper. The protrusion of the dot is achieved through a process of embossing. A cell consists of six dots arranged in the form of a rectangular grid of two dots horizontally and three dots vertically. With six dots arranged this way, one can obtain sixty three different patterns of dots. A visually Handicapped person is taught Braille by training him or her in discerning the cells by touch, accomplished through his or her fingertips. The image below shows how this is done.

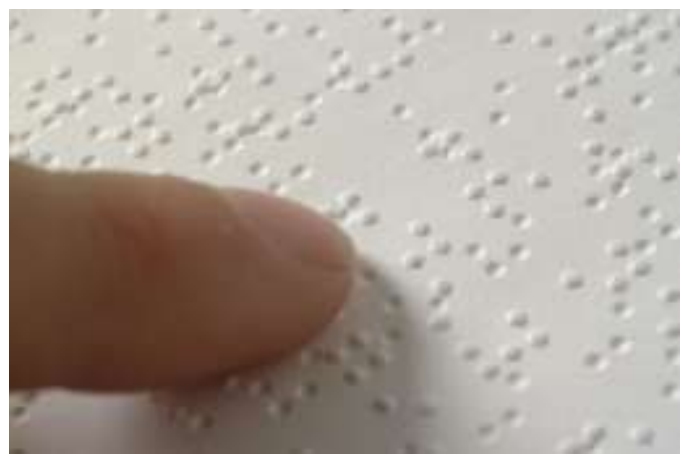

Fig. 1 Braille sheet

Each arrangement of dots is known as a cell and will consist of at least one raised dot and a maximum of six.

\section{The Braille Cell}

A printed sheet of Braille normally contains upwards of twenty five rows of text with forty cells in each row. The physical dimensions of a standard Braille sheet are approximately 11 inches by 11 inches. The dimensions of the Braille cell are also standardized but these may vary slightly depending on the country. The dimension of a Braille cell, as printed on an embosser is shown below. 
Braille Cell Dimensions

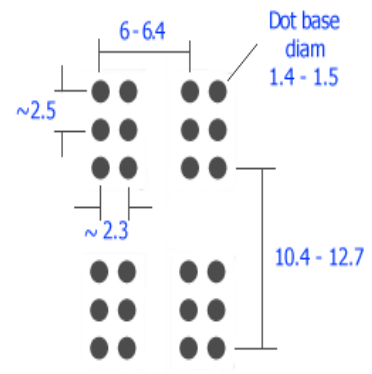

All dimensions are in Millimeters

Fig. 2 A Braille cell

The six dots forming the cell permit sixty three different patterns of dot arrangements. Strictly, it is sixty four patterns but the last one is a cell without any dots and thus serves the purpose of a space. A Braille cell is thus an equivalent of a six bit character code, if we view it in the light of text representation in a computer! However, it is not related to any character code in use with computers.

\section{Standard English Braille}

In standard English Braille, many of the sixty three cells will correspond to a letter of the Roman alphabet, or a punctuation mark. A few cells will represent short words or syllables that are frequently encountered in English. This is done so that the number of cells required to show a sentence may be reduced, which helps minimize the space requirements while printing Braille.

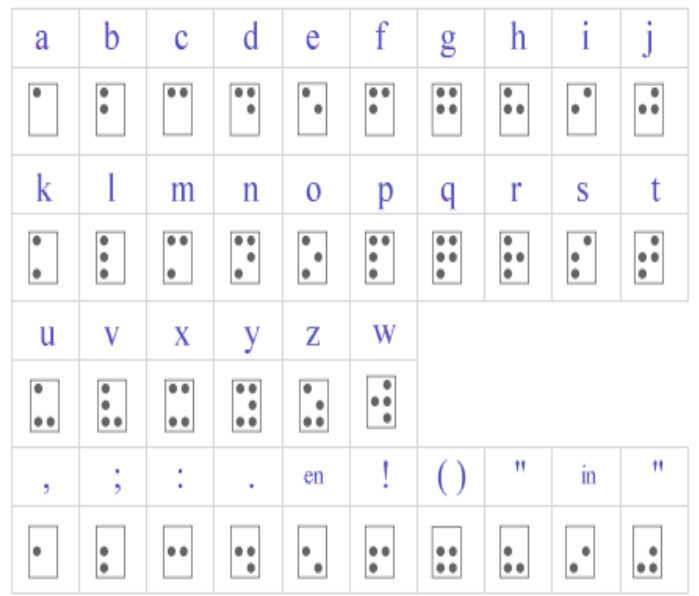

Fig. 3 Letters and Special symbols of Braille

\section{COMPARISON ABOUT BRAILLE CELL AND BRAILLE HAND GLOVE}

(Basic Idea behind the Braille Glove)
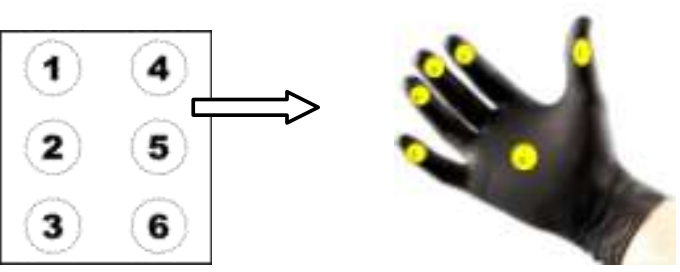

Fig. 4 Hand glove with six positions

The six dots forming the cell permit sixty three different patterns of dot arrangements. It is matched with alphabets, numbers and special symbols of the English language. The Braille glove contains six vibration motors. These are fixed in five fingers and center palm. The basic technique used in the hand glove based on retrieval value of English letter value from the user typed in the keyboard. It is converted into Braille value and activated the corresponding motors. So based on the position of vibration the blind person can understand the value of the letter. For example if the user can type the letter " $r$ ". It is converted int Braille value as 1,2,3,5 and this value activates the corresponding motors in Braille hand glove. This conversion program in written in high tech $\mathrm{C}$ language and it is recorded in micro controller of the hand glove. Any blind person can wear this glove in right hand, and understand the English letters through vibration instead of touch the Braille sheet. Similarly the whole word or sentence is converted into Braille vibration and send to blind person. Based on this method the visible person and deaf and blind person can communicate effectively.

\section{THE DESIGN CONCEPT}

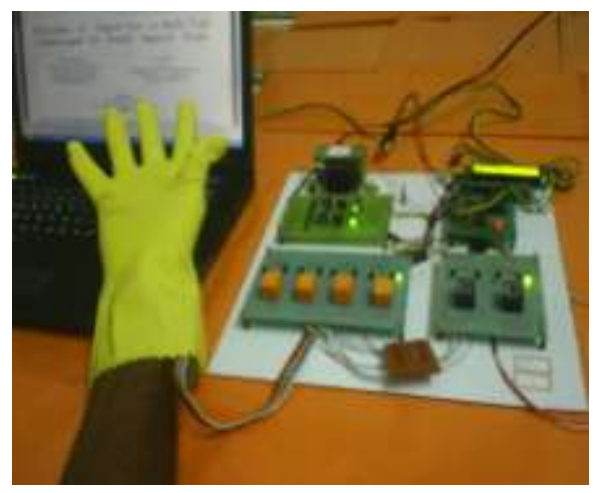

Fig. 5 Vibration Hand glove 
The Braille Hand glove will be comprised of the following key components
1. 89C51 Micro controller
2. RS $232 \mathrm{C}$
3. Relay Driver and Relay
4. power supplies
5. Vibrator motor in hand glove

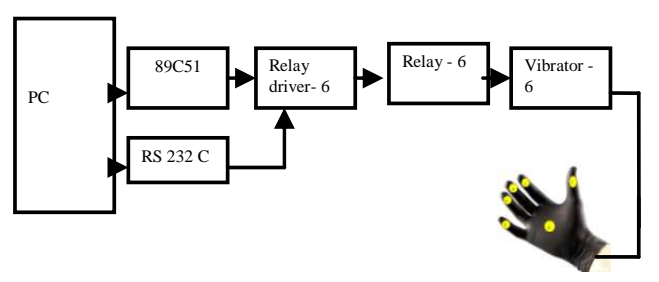

Fig. 6 Block diagram of Braille hand glove

\section{A. Micro controller}

Microcontroller is a general purpose device, which integrates a number of the components of a microprocessor system onto single chip. It has inbuilt CPU, memory and peripherals to make it as a mini computer. A microcontroller is integrated with

1. CPU Core

2. RAM and ROM

3. Some parallel digital i/o ICs

The vibration hand glove contains a microcontroller AT89C51. It is the 40 pins, 8 bit Microcontroller manufactured by Atmel group. It is the flash type reprogrammable memory. Advantage of this flash memory is we can erase the program within a few minutes. It has $4 \mathrm{~KB}$ on chip ROM and 128 bytes internal RAM and 32 I/O pin as arranged as port 0 to port 3 each has 8 bit bin .Port 0 contains 8 data line(D0-D7) as well as low order address line(AO-A7).

The position identification and controlling the motors is programmed in hi tech c language and is loaded in microcontroller.

\section{1) Crystal:}

The heart of the micro controller is the circuitries which generate the clock pulse. Then micro controller provides the two pins. XTAL 1, XTAL 2 to correct the external crystal resonator along with capacitor. The crystal frequency is the basic clock frequency of the microcontroller. Based on the frequency rotation time of vibration motor inside the hand glove is controlled by micro controller.

\section{2) Reset:}

The memory location for $89 \mathrm{C} 510000 \mathrm{H}$ to $0 \mathrm{FFFH}$. Whenever switch on the supply the memory location starts from $0000 \mathrm{H}$. The $89 \mathrm{C} 51$ micro controller provide $9^{\text {th }}$ pin for Reset Function. Here the reset circuitry consists of 10Mf capacitor in series with $10 \mathrm{~K}$ resister. When switch on the supply the capacitor is changed and discharged gives high low pulse to the $9^{\text {th }}$ pin through the 7414 inverter. Here we interface LCD display to microcontroller via port 0 and port 2. LCD control lines are connected in port 2 and Data lines are connected in port 0 . whenever struggle in motor speed, it is used to restart the program.

\section{3) $L C D$ :}

Liquid Crystal Display has 16 pins in which first three and $15^{\text {th }}$ pins are used for power supply. $4^{\text {th }}$ pin is RS(Register Selection) if it is low data and if it is high command will be displayed. $5^{\text {th }}$ pin is $\mathrm{R} / \mathrm{W}$ if it is low it performs write operation. $6^{\text {th }}$ pin act as enable and remaining pins are data lines

\section{B. RS232 Communication}

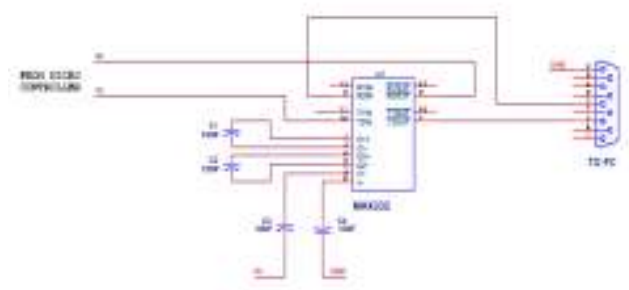

Fig. 7 circuit diagram of RS232

In viberation hand glove RS-232 is a standard for serial binary data interconnection between a DTE (Data terminal equipment) and a DCE (Data Circuit-terminating Equipment). It is commonly used in computer serial ports.Here ascii values are converted into binary signals and send to viberation glove to activates the viberation motors.

Details of the character format and transmission bit rate are controlled by the serial port hardware, often a single integrated circuit called a UART that converts data from parallel to serial form. A typical serial port includes specialized driver and receiver integrated circuits to convert between internal logic levels and RS-232 compatible signal levels. 


\section{Relay:}

A relay is an electrically operated switch. Current flowing through the coil of the relay creates a magnetic field which attracts a lever and changes the switch contacts. The coil current can be on or off so relays have two switch positions and they are double throw (changeover) switches. The coil of a relay passes a relatively large current, typically $30 \mathrm{~mA}$ for a $12 \mathrm{~V}$ relay, but it can be as much as $100 \mathrm{~mA}$ for relays designed to operate from lower voltages. Most ICs (chips) cannot provide this current and a transistor is usually used to amplify the small IC current to the larger value required for the relay coil. The maximum output current for the popular 555 timer IC is $200 \mathrm{~mA}$ so these devices can supply relay coils directly without amplification.

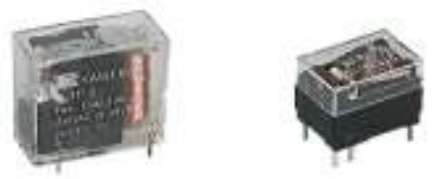

Fig. 8 Relay

Relays are usually SPDT or DPDT but they can have many more sets of switch contacts, for example relays with 4 sets of changeover contacts are readily available. Most relays are designed for PCB mounting but you can solder wires directly to the pins providing you take care to avoid melting the plastic case of the relay. The animated picture shows a working relay with its coil and switch contacts. This lever moves the switch contacts. There is one set of contacts (SPDT) in the foreground and another behind them, making the relay DPDT.

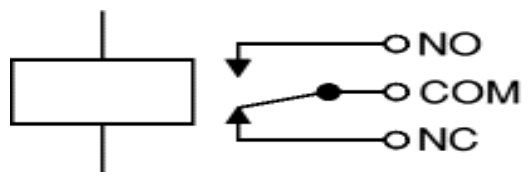

Fig. 9 Relay-Switch connection

The relay's switch connections are usually labeled COM, NC and NO:

- $\quad \mathbf{C O M}=$ Common, always connect to this, it is the moving part of the switch.

- $\quad \mathbf{N C}=$ Normally Closed, COM is connected to this when the relay coil is off.
- $\quad \mathbf{N O}=$ Normally Open, COM is connected to this when the relay coil is on.

\section{Power supplies}

A block diagram containing the parts of a typical power supply and the to a transformer, which steps that ac voltage down to the level for the desired dc output. A diode voltage at various points in the unit is shown in fig 19.1. The ac voltage, typically $120 \mathrm{~V} \mathrm{rms}$, is connected rectifier then provides a full-wave rectified voltage that is initially filtered by a simple capacitor filter to produce a dc voltage. This resulting dc voltage usually has some ripple or ac voltage variation. A regulator circuit can use this de input to provide a de voltage that not only has much less ripple voltage but also remains the same dc value even if the input dc voltage varies somewhat, or the load connected to the output dc voltage changes. This voltage regulation is usually obtained using one of a number of popular voltage regulator IC units.

\section{E. Vibrator Motors}

The main component in Braille glove is vibration motor. it is configured in two basic varieties ie coin (or flat) and cylinder (or bar). Cylinder type motors are simple brush motors with a traditional axial design. The eccentric movement of the weight attached to the rotor provides vibration during operation. In Braille glove it is best suited in finger positions. The amount of vibration is directly proportional to the voltage applied to the motor. Cylinder motors are manufactured in high volumes and are fairly inexpensive. An electrical current applied to the coil in the direction of the arrow generates upward force on the left side of the coil and downward force on the right side, causing the coil to revolve clockwise.

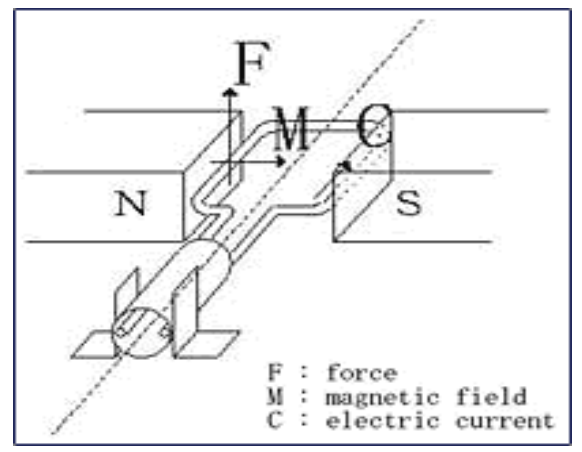

Fig. 10 working principle of viberation motor 


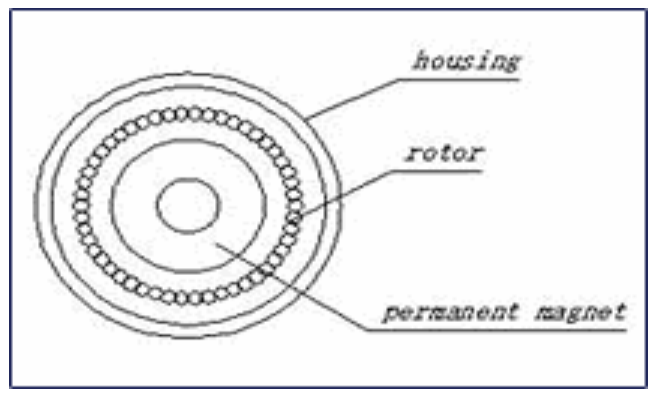

Fig. 11 cross section of coreless motors

1) Principles of vibration:

An offset counterweight is fitted to the end of the motor shaft. When the shaft turns, the imbalance in the counterweight causes the handset to vibrate.

\begin{tabular}{|c|c|c|c|}
\hline \multicolumn{2}{|c|}{ Counter Weight } & Speed[rpm & Vibration[N] \\
\hline \multirow{2}{*}{$4 \mathrm{CH}$} & $\begin{array}{c}\mathrm{R} 2.5 \times \mathrm{L} 3.5 \times 18 \\
0^{\circ}\end{array}$ & 9500 & 1.50 \\
\hline & $\begin{array}{c}\mathrm{R} 3.0 \times \mathrm{L} 3.5 \times 15 \\
0^{\circ}\end{array}$ & 9500 & 2.18 \\
\hline $4 \mathrm{CR}$ & $\begin{array}{c}\mathrm{R} 3.0 \times \mathrm{L} 4.0 \times 15 \\
0^{\circ}\end{array}$ & 9500 & 2.56 \\
\hline \multirow{2}{*}{$\begin{array}{l}4.4 \mathrm{C} \\
\mathrm{H}\end{array}$} & $\begin{array}{c}\mathrm{R} 3.0 \times \mathrm{L} 4.0 \times 15 \\
0^{\circ}\end{array}$ & 7400 & 1.91 \\
\hline & $\begin{array}{c}\mathrm{R} 3.0 \times \mathrm{L} 4.0 \times 15 \\
0^{\circ}\end{array}$ & 8500 & 2.37 \\
\hline
\end{tabular}

\section{CONCLUSION AND FURTHER WORK SUGGESTED}

The development of low cost Braille hand glove is necessary for visually impaired community. A number of private translation kits exist, but their private ownership restricts open development. The same technique can be used in various languages like Bengali, Hindi, Tamil, French, etc., other developments like through signal, and the blind can also convey reply to visible person produce the vibration hand glove as the best kit for two way communication.

\section{REFERENCES}

[1] Basu SG ,lachikawa A (2004), Dialogue Languages and Persons with Disabilities, IEICE transactions, Vol. E87-D, No 6, pp 31-43.

[2] Blenkhorn (1995), A system for converting Braille into print, IEEE Transactions on Rehabilitation Engineering, Vol. 3 no 2, pp 215-221.

[3] Choi H Lee W (2004), Tactile Display as Braille Display for the Visually Disabled, in proceedings of IEEE/RSJ
International Conference on Intelligent Robotics and Systems, pp 1985-1990.

[4] Fritz J P Barner (1999), Design of a Hepatic Visualization System for People with Visual Impairments, IEEE Transactions on Rehabilitation Engineering, vol. 7, No 3 pp 372-384

[5] Fukumoto et al (1997), Body coupled Finger Ring wireless wearable keyboard, proceeding of the ACM conference on Human factors in computing systems ,France, pp 147-154 .

[6] Gill J M (1992), priorities for technical research and development for visually disabled persons, world Blind Union Res. Committee .

[7] Golding P (1998), Design Study on a Braille Typewriter, Western Australia, Curtin University of Technology.

[8] Slaby W A(1990), Computerized Braille translation, Microcomputer Applications, Vol.13,pp 107-113.

[9] Sleng C Lau Y(1999)., Regular feature extraction for recognition of Braille. In Third international conference on Computational Intelligence and Multimedia Applications,ICCIM'99 Proceedings, pp 302-308.

[10] Werner H(1992), Automatic Braille production by means of computer in uses of computers in Aiding the Disabled, North Holland, pp 321-336.

\section{AUTHORS PROFILE}

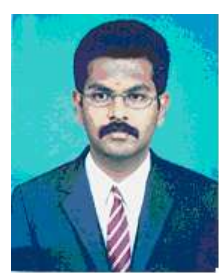

M.Rajasenathipathi (senathi_pathi@yahoo.co.in) is a third year Doctoral Research Scholar in the Research and Development Centre of Bharathiar University. He received his Master degree in computer Applications and M.Phil degree in computer science from M.K. University. He is also working as an Assistant Professor of Computer Science at N.G.M.College, Pollachi, India. He has been an active developer of systems for people with disabilities for the past 10 years.

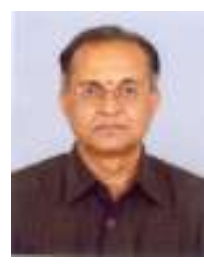

M.Arthanari (arthanarimsvc@gmail.com) holds a Ph.D in Mathematics from Madras University as well as Masters degree in Computer Science from BITS, Pilani. He has worked as a Professor and Head, Department of CSE and IT in Tejaa Shakthi Institute of Technology for Women, Coimbatore, India and Head of the Institution in various colleges in India, He holds a patent issued by the Govt. of India for the invention in the field of Computer Science. He has directed teams of Ph.D researchers and industry experts for developing patentable products. $\mathrm{He}$ teaches strategy, project management, creative problem solving, innovation and integrated new product development for last 35 years. 


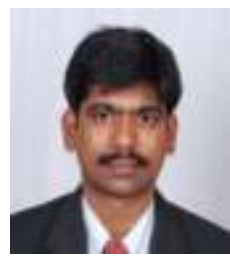

Sivakumar.M (sivala@gmail.com) has $10+$ years of experience in the software industry including Oracle Corporation. He received his Bachelor degree in Physics and Masters in Computer Applications from the Bharathiar University, India. He holds a patent for the invention in embedded technology. He is technically certified by various professional bodies like ITIL, IBM Rational Clear case Administrator, OCP - Oracle Certified Professional 10g and ISTQB. 